\title{
Thermoelectric hydrogen sensors using Si and SiGe thin films with a catalytic combustor
}

\author{
Maiko NISHIBORI, ${ }^{\dagger}$ Woosuck SHIN, Noriya IZU, Toshio ITOH, Ichiro MATSUBARA, \\ Nobuyuki WATANABE* and Toshihiro KASUGA* \\ National Institute of Advanced Industrial Science and Technology (AIST) Shimo-Shidami, Moriyama-ku, Nagoya 463-8560 \\ *Nagoya Institute of Technology, Department of Frontier Materials Gokiso, Syowa-ku, Nagoya 466-8555
}

\begin{abstract}
Micro-machined thermoelectric hydrogen sensors (micro-THS) with catalyst combustors were fabricated using $\mathrm{Si}$ and $\mathrm{SiGe}$ thin films prepared using the sputtering or chemical vapor deposition methods, and the relationship between the thermoelectric property of the films and the performance of the sensors were investigated. The Seebeck coefficients of the $\mathrm{Si}$ and $\mathrm{SiGe}$ films were evaluated as $107-246$ and $82-126 \mu \mathrm{V} / \mathrm{K}$ at temperatures of $50-480^{\circ} \mathrm{C}$. The combustion heat estimated by increasing the temperature of the catalyst on the micro-THS with the Si thin film was 7-20\% smaller than that of SiGe thin film. Moreover, the voltage signal of the micro-THS with the Si thin film was 8-13\% larger than that of SiGe thin film. Both the Seebeck coefficient of the Si thin films and the voltage signal of the micro-THSs with the Si TE films were better than those of the SiGe thin film, although the combustion heat of the catalyst on the micro-THSs with the Si thin films was smaller compared to that with the SiGe thin film. For the micro sensor application using the thermoelectric thin film, the Seebeck coefficient is the most important factor to improve the sensor performance.
\end{abstract}

(02010 The Ceramic Society of Japan. All rights reserved.

Key-words : Hydrogen sensor, Si thin film, Thermoelectric, Catalyst combustion

[Received November 25, 2009; Accepted January 15, 2010]

\section{Introduction}

Hydrogen gas is the most attractive and suitable candidate for a future fuel and an energy carrier because it burns cleanly. Although hydrogen used as fuel has the advantage of having a small environmental load, it has the disadvantage of being highly explosive. Therefore, hydrogen sensors have been developed to monitor hydrogen concentrations in the atmosphere and to detect hydrogen leakage from storage to ensure safety and security.

Commercially available combustible gas sensors, including hydrogen sensors, are mostly catalytic-combustion-type sensors using catalyst-coated platinum wire, or semiconductor types, using metal oxides, for example, stannic oxide, which detect gases via variations in their resistance. ${ }^{1,2)}$ These sensors need to be heated to around $400^{\circ} \mathrm{C}$ in order to maintain proper operation, and principally have poor selectivity for hydrogen gas against other combustible gases. Hydrogen sensors that can quickly and reliably detect hydrogen over a wide range of concentrations have not been available.

Recently, we have proposed a micro thermoelectric hydrogen sensor (micro-THS) $)^{3)-5)}$ and demonstrated its sensing performance. The micro-THS has a unique and reliable working principle, a synergetic combination of catalytic combustion of hydrogen and thermoelectric conversion, and is one promising solution for detecting wide-ranging hydrogen concentrations in the air. The catalyst integrated on the micro-THS converts hydrogen and oxygen into water with the release of exothermic heat. This combustion heat results in a temperature gradient $(\Delta \mathrm{T})$ across the TE thin film, and this gradient is converted into a voltage signal $(\Delta \mathrm{V})$

Corresponding author: M. Nishibori; E-mail: m-nishibori@aist. go.jp using the Seebeck effect.

In our previous work, we developed thin film-type TE materials with heavily doped silicon-germanium alloys (SiGe) and applied the SiGe thin film to the micro-THS. ${ }^{6), 7)}$ We could detect a very wide range of $\mathrm{H}_{2}$ concentrations in air, from as low as 0.5 ppm, up to as high as 5 vol. $\% \mathrm{H}_{2}$ in air. ${ }^{8}$ Furthermore, we have carried out selective measurements of $\mathrm{H}_{2}$ in the human breath with this THS system. ${ }^{9)}$

For the sensor device application using thermoelectric (TE) thin film, it is important that the TE thin film has high thermoelectric properties, which are the key parameters for gas sensing performance. Materials based on $\mathrm{BiTe}, \mathrm{PbTe}, \mathrm{Si}$, and $\mathrm{SiGe}$ emerged as the best thermoelectric materials for operating temperatures of between 450 and $1400 \mathrm{~K}$. Among them, Si and $\mathrm{SiGe}$ are compatible with micro fabrication, such as the processing of micro-THS, and $\mathrm{Si}$ and SiGe thin films can be prepared using various methods. In our previous studies, due to the higher thermal conductivity of $\mathrm{Si},{ }^{10), 11)} \mathrm{SiGe}$ with lower thermal conductivity $^{7}$ has been used for application in the micro-THS.

In this study, we prepared an Si thin film using two different film preparation techniques, the long-through-type helicon sputtering method, and the Low Pressure Chemical Vapor Deposition (LPCVD) method, and fabricated the micro-THSs using these $\mathrm{Si}$ TE thin films. We then evaluated the thermoelectric properties of these films and the sensing performance of the micro-THSs with the Si thin films. A comparison with the results from the SiGesputtering TE thin film was also carried out and is discussed here.

\section{Experimental}

The Si thin films were prepared by a commercially available LPCVD method and the helicon sputtering method (isp-2000- 
HC1-SS, ULVAC, Inc.). The Si-LPCVD thin film was deposited on an $\mathrm{Si}_{3} \mathrm{~N}_{4} / \mathrm{SiO}_{2}$ multilayer on $\mathrm{Si}$ substrate at $1000^{\circ} \mathrm{C}$ by a silane source at a deposition pressure of several $10^{2} \mathrm{~Pa}$. The doping process was carried out by Boron ion implantation, $2.0 \times 10^{15} \mathrm{~cm}^{2}$, and post-annealing at $1000^{\circ} \mathrm{C}$. The thickness of the Si-LPCVD film was checked using a stylus profile measuring system and shown to be $410 \mathrm{~nm}$.

The Si-sputtering thin film was also deposited on an $\mathrm{Si}_{3} \mathrm{~N}_{4} /$ $\mathrm{SiO}_{2}$ multilayer on $\mathrm{Si}$ substrate at an RF power of $75 \mathrm{~W}$, with an Ar gas flow of $25 \mathrm{~mL} / \mathrm{min}$, and the substrate temperature was maintained at $450^{\circ} \mathrm{C}$. A sintered target of 1 at.\% B-doped Si (ptype) was used for the deposition of the Si films. Since the asdeposited Si thin film was amorphous, the thermal annealing was carried out at $1050^{\circ} \mathrm{C}$ for $5 \mathrm{~h}$ in an Ar flow atmosphere. The thickness of the film was checked to be $600 \mathrm{~nm}$.

For comparison, we also prepared an SiGe thin film by the helicon sputtering method with an RF power of $150 \mathrm{~W}$ in an Ar gas flow of $25 \mathrm{~mL} / \mathrm{min}$, and the substrate temperature was maintained at $150^{\circ} \mathrm{C}$. A sintered target of 1 at.\% B-doped $\mathrm{Si}_{0.8} \mathrm{Ge}_{0.2}$ (p-type) was used for the deposition of the SiGe films. Since the as-deposited $\mathrm{SiGe}$ thin film was amorphous, the thermal annealing was carried out at $1050^{\circ} \mathrm{C}$ for $5 \mathrm{~h}$ in an Ar flow atmosphere. The thickness of the film was checked to be $420 \mathrm{~nm}$.

The characterization of the prepared thin film was carried out using an X-ray diffractometer with $\mathrm{Cu} \mathrm{K} \alpha$ irradiation (XRD; Rigaku Co., RINT2100). Thermoelectric properties were measured using a commercial TE measurement system (RZ20001i, Ozawa Science Co., Ltd.). The system has been designed with 4-point pressure-contact electrode probes for the measurement of the conductivity, $\sigma$, and Seebeck coefficient, $\alpha$, of thin film samples. ${ }^{12)}$

Figure 1 shows a photo of the micro-THS mounted on a metal stem. Fabrication of the micro-THS devices was based on the process used in a previous study. ${ }^{13), 14)}$

$\mathrm{The} \mathrm{Pt} / \mathrm{Al}_{2} \mathrm{O}_{3}$ catalyst was prepared by impregnation of a commercial alumina powder with an aqueous solution of $\mathrm{PtCl}_{4} \cdot 5 \mathrm{H}_{2} \mathrm{O}$. ${ }^{15)}$ The $\mathrm{Pt}$ content of the $\mathrm{Pt} / \mathrm{Al}_{2} \mathrm{O}_{3}$ catalyst in this study was fixed at $40 \mathrm{wt} . \%$. A drop of the catalyst paste was deposited on the thin membrane of the micro-THS using an air
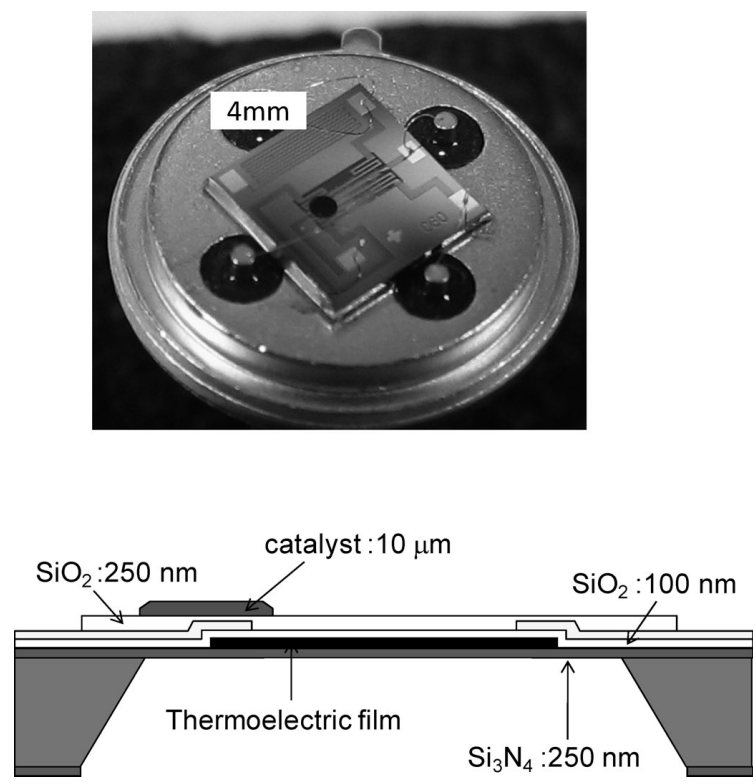

Fig. 1. Photograph of the micro-THS mounted on a metal stem. dispenser (MUSASHI Engineering Inc.). The catalyst paste deposited on the micro device was then baked in air at $300^{\circ} \mathrm{C}$ for $2 \mathrm{~h}$. The thickness of this catalyst after the baking was estimated at approximately $10 \mu \mathrm{m}$.

The gas response performance was investigated using a gasflow-type test chamber. Sensor response was recorded by alternately flowing a dry target gas mixture and dry air into the flowtype chamber at a flow rate of $200 \mathrm{~mL} / \mathrm{min}$. The performance test of the micro-THS was carried out by gas mixtures of $1 \mathrm{vol} . \% \mathrm{H}_{2}$ in air. Thermal properties of the micro-THSs were explored with an infrared (IR) camera (LAIRD-270A, Nikon). Artificial errors due to the differing IR emissivity of different catalyst materials were considered and calibrated to be below $1^{\circ} \mathrm{C}$.

When the catalyst oxidizes $\mathrm{H}_{2}$ gas and releases combustion heat, $\Delta \mathrm{T}$ develops between the surface temperature of the catalyst, hot-side, and the TE line, cold-side, on the micro-THS device. This $\Delta \mathrm{T}$ is converted into $\Delta \mathrm{V}$ depending on the magnitude of the Seebeck coefficient, $\alpha$, of a thermoelectric thin film, as follows:

$$
\Delta \mathrm{V}=\alpha \Delta \mathrm{T}
$$

From the $\Delta \mathrm{T}$ and the $\Delta \mathrm{V}$ of the micro-THS, we could evaluate the apparent $\alpha$ of the $\mathrm{Si}$ and $\mathrm{SiGe}$ thin films.

\section{Results and discussion}

Figure 2 shows the XRD patterns of the prepared thin films of (a) Si-sputtering, (b) Si-LPCVD, and (c) SiGe-sputtering deposited on the $\mathrm{Si}_{3} \mathrm{~N}_{4} / \mathrm{SiO}_{2} / \mathrm{Si}$ substrate. All of these thin films have a diamond structure. The diffraction peaks of the $\mathrm{Si}$ and SiGe thin films prepared by sputtering corresponding to the (111), (220), and (311) planes with $2 \theta$ of 28,47 , and $55^{\circ}$ were observed with the same X-ray intensity ratio as in the case of their powder patterns. On the other hand, the diffraction peak of the Si-LPCVD film corresponding to the (220) planes with $2 \theta$ of $47^{\circ}$ became strong compared to the other peaks. This suggests that the grains of the Si-LPCVD thin film were oriented.

Figure 3 shows the thermoelectric properties of the TE thin films, (a) Si-sputtering, (b) Si-LPCVD, and (c) SiGe-sputtering. The Seebeck coefficient, $\alpha$, and the conductivity, $\sigma$, were mea-

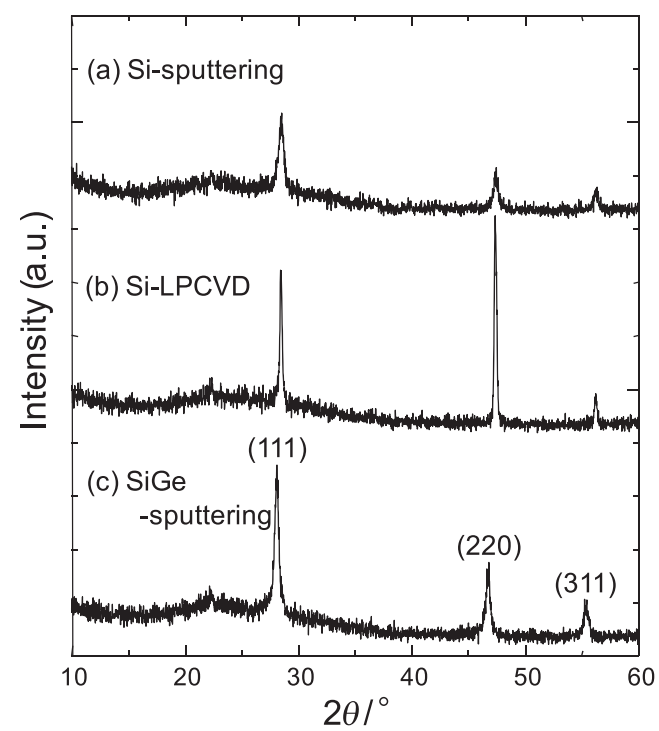

Fig. 2. XRD patterns of the prepared thin films: (a) Si-sputtering, (b) Si-LPCVD, and (c) SiGe-sputtering deposited on the $\mathrm{Si}_{3} \mathrm{~N}_{4} / \mathrm{SiO}_{2} / \mathrm{Si}$ substrate. 


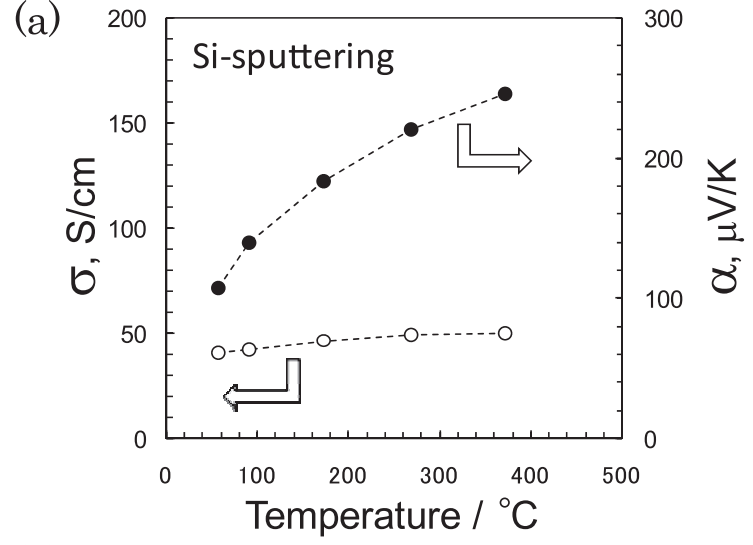

(b)

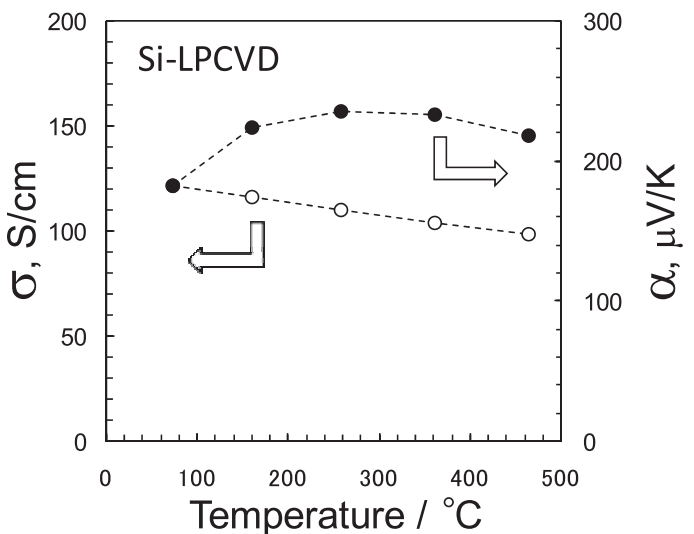

(c)

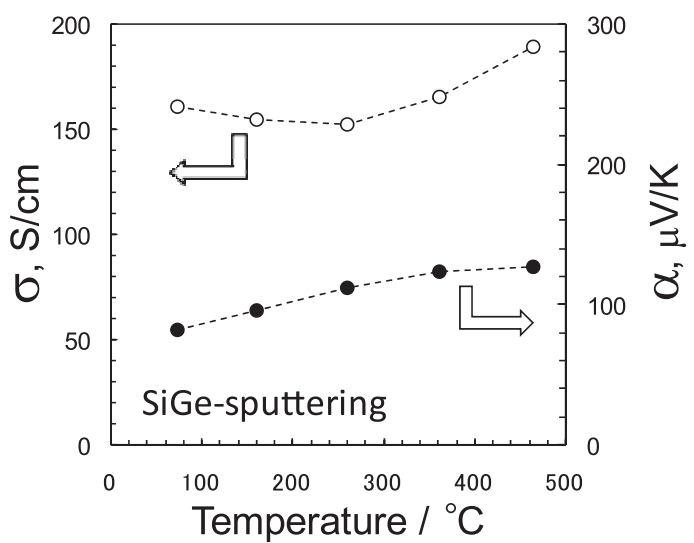

Fig. 3. Thermoelectric properties of the TE thin films: (a) Si-sputtering, (b) Si-LPCVD, and (c) SiGe-sputtering.

sured from 50 to $480^{\circ} \mathrm{C}$ in air.

The $\alpha$ of the Si-sputtering thin film and Si-LPCVD thin film increased with temperature, ranging from 107 to $246 \mu \mathrm{V} / \mathrm{K}$ and from 182 to $235 \mu \mathrm{V} / \mathrm{K}$, respectively. The temperature dependence of $\alpha$ of the Si-LPCVD thin film was smaller than that of the Si-sputtering thin film. The $\sigma$ of the Si-sputtering thin film was $42 \mathrm{~S} / \mathrm{cm}$ at $90^{\circ} \mathrm{C}$ and was almost temperature independent. However, the $\sigma$ of the Si-LPCVD thin film was $121 \mathrm{~S} / \mathrm{cm}$ at $72^{\circ} \mathrm{C}$ and decreased with temperature. This difference of the $\sigma$ between the Si-LPCVD and the Si-sputtering could be explained by the doping level. The metallic behavior obtained for SiLPCVD thin film is typical for high-doping Si film.

The $\alpha$ of the SiGe-sputtering thin film increased with temperature, ranging from 82 to $126 \mu \mathrm{V} / \mathrm{K}$ and was much smaller than that of the Si-sputtering and Si-LPCVD thin films. The $\sigma$ of the SiGe-sputtering thin film was $161 \mathrm{~S} / \mathrm{cm}$ at $73^{\circ} \mathrm{C}$ and increased (a)

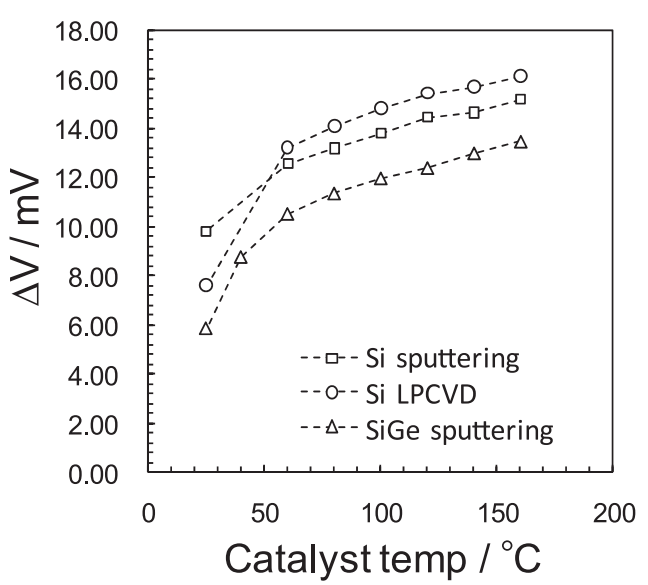

(b)

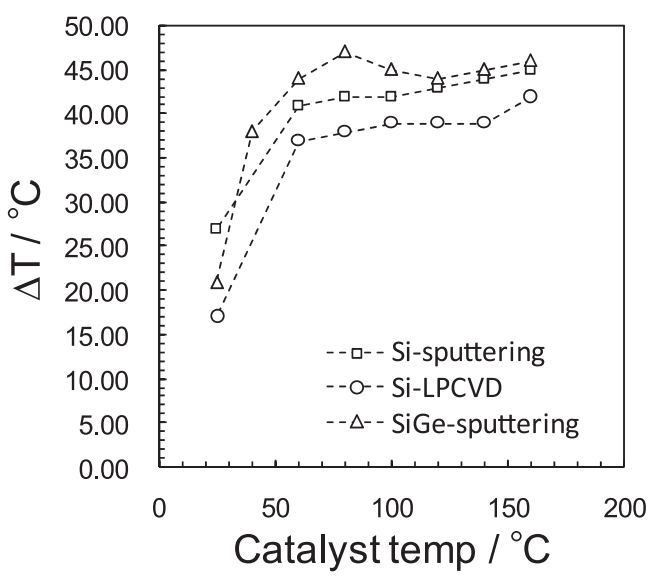

Fig. 4. Temperature dependence of (a) voltage signal, $\Delta \mathrm{V}$, and (b) temperature change, $\Delta \mathrm{T}$, from the micro-THS with a $\mathrm{Pt} / \mathrm{Al}_{2} \mathrm{O}_{3}$ catalyst for 1 vol. $\% \mathrm{H}_{2}$ in air at a flow rate of $200 \mathrm{~mL} / \mathrm{min}$. Various Si-sputtering, SiLPCVD, and SiGe-sputtering films were used as the TE thin films of these micro-THSs.

with temperature.

The thermoelectric power factor (PF), $\alpha^{2} \sigma$, of the Si-sputtering, Si-LPCVD, and SiGe-sputtering thin films were estimated to be $0.82,4.01$, and $1.31 \times 10^{-4} \mathrm{~W} / \mathrm{mK}^{2}$ at temperatures of 90,72 , and $73^{\circ} \mathrm{C}$, respectively. The PF of the Si-LPCVD thin film was five times as large as that of the Si-sputtering thin film due to the difference of $\sigma$ between Si-LPCVD and Si-sputtering, although the $\alpha$ of the Si-LPCVD thin film was almost the same as the $\alpha$ of the Si-sputtering thin film at temperatures over $200^{\circ} \mathrm{C}$.

Figure 4 shows the dependence on catalyst temperature of (a) the temperature difference, $\Delta \mathrm{T}$, and (b) the voltage signal, $\Delta \mathrm{V}$, from the micro-THS with the three different TE films with a Pt/ $\mathrm{Al}_{2} \mathrm{O}_{3}$ catalyst for the gas mixture of 1 vol. $\% \mathrm{H}_{2}$ in air at a flow rate of $200 \mathrm{~mL} / \mathrm{min}$. When $\mathrm{H}_{2}$ was introduced, the catalyst temperature (hot-side) increased with $\mathrm{H}_{2}$ combustion, and $\Delta \mathrm{T}$ built up across the TE line temperature (cold-side). The greater the temperature difference across the TE line, the higher $\Delta \mathrm{T}$ could build up.

For 1 vol. $\% \mathrm{H}_{2}$ in air, the $\Delta \mathrm{T}$ of the micro-THS using the TE thin film of Si-sputtering, Si-LPCVD, and SiGe-sputtering was 42,35 , and $45^{\circ} \mathrm{C}$, respectively. Because the dimensions of the catalyst integrated on these devices were the same, the difference in $\Delta \mathrm{T}$ between these micro-THSs arises from differences in the 
Table 1. Summary of Thermoelectric Properties of the Si and SiGe Thin Films and Sensing Performances of the Micro-THSs

\begin{tabular}{lrrccccc}
\hline & \multicolumn{4}{c}{ Thin film } & \multicolumn{3}{c}{ Device } \\
\cline { 2 - 8 } & $\begin{array}{c}\sigma \\
(\mathrm{S} / \mathrm{cm})\end{array}$ & $\begin{array}{c}\alpha \\
(\mu \mathrm{V} / \mathrm{K})\end{array}$ & $\begin{array}{c}\mathrm{PF} \\
\left(10^{-4} \mathrm{~W} / \mathrm{mK}^{2}\right)\end{array}$ & $\begin{array}{c}\kappa \\
(\mathrm{W} / \mathrm{mK})\end{array}$ & $\begin{array}{c}\Delta \mathrm{V} \\
(\mathrm{mV})\end{array}$ & $\begin{array}{c}\Delta \mathrm{T} \\
\left({ }^{\circ} \mathrm{C}\right)\end{array}$ & $\begin{array}{c}\Delta \mathrm{V} / \Delta \mathrm{T} \\
(\mu \mathrm{V} / \mathrm{K})\end{array}$ \\
\hline Si-sputtering & 42.3 & 139.5 & 0.82 & - & 13.77 & 42 & 330 \\
Si-LPCVD & 121.2 & 182.0 & 4.01 & $31.2 \pm 3.7^{10)}$ & 14.81 & 35 & 380 \\
SiGe-sputtering & 161.9 & 90.0 & 1.31 & $2.5^{7)}$ & 11.99 & 45 & 270 \\
\hline
\end{tabular}

thermal conductivity $(\kappa)$ of the various TE thin films. The $\kappa$ of the SiGe thin film is much lower than that of the Si (around 31.2 $\mathrm{W} / \mathrm{mK}){ }^{10)}$ The reported values of the $\kappa$ of SiGe thin films are around $2.5 \mathrm{~W} / \mathrm{mK}$ (by sputtering) ${ }^{7}$ and around $11 \mathrm{~W} / \mathrm{mK}$ $(\mathrm{CVD}){ }^{10)}$ which shows that the $\kappa$ of the sputtering thin film becomes smaller than that of the CVD thin film. Therefore, it is expected that the $\kappa$ of the Si-LPCVD thin film becomes higher than that of the Si-sputtering thin film, and the $\Delta \mathrm{T}$ of the microTHS using the Si-LPCVD thin film is small compared with that of the $\mathrm{Si}$ - and $\mathrm{SiGe}$-sputtering thin films.

On the other hand, the $\Delta \mathrm{V}$ of the micro-THS with Si-sputtering thin films was approx. $13 \%$ larger than that of the micro-THS with SiGe-sputtering TE thin film. The $\Delta \mathrm{V}$ of micro-THS using the Si-LPCVD thin film was approx. $8 \%$ larger than that of the micro-THS using the Si-sputtering thin film.

Table 1 shows a summary of the thermoelectric properties of the $\mathrm{Si}$ and $\mathrm{SiGe}$ thin films and sensing performances of the micro-THSs using these TE thin films. The thermoelectric properties of the Si-sputtering, Si-LPCVD, and SiGe-sputtering thin films were measured at 90,72 , and $73^{\circ} \mathrm{C}$ in air, respectively. The sensing performances of the micro-THSs using these TE thin films were tested at the catalyst temperature of $100^{\circ} \mathrm{C}$ for $1 \mathrm{vol} . \%$ $\mathrm{H}_{2}$ in air.

The apparent $\alpha(\Delta \mathrm{V} / \Delta \mathrm{T}$ listed in Table 1$)$ evaluated from the $\Delta \mathrm{V}$ and $\Delta \mathrm{T}$ of the micro-THSs using the Si-sputtering, SiLPCVD, and SiGe-sputtering are 330, 380, and $270 \mu \mathrm{V} / \mathrm{K}$, respectively, which were much larger than the measurements for $\alpha$ of the thin films. It appears that the temperature of the catalyst surface is different from that of the catalyst bottom which is in contact with the TE thin film. The temperature of the catalyst bottom is directly related to the sensing performance. Therefore, this is due to the temperature difference across the catalyst thickness deposited on the device, and the apparent $\alpha$ is higher than the measured property. The difference of $\Delta \mathrm{V}$ for these microTHSs corresponded to the $\alpha$ of various TE thin films, regardless of the $\kappa$ of these thin films. As expected from previous studies, ${ }^{10), 16), 17)}$ the benefit of poly-SiGe comes from its lower thermal conductivity compared to pure poly-Si ${ }^{10)}$ However, for the micro sensor application using the TE thin film, we suggest that the Seebeck coefficient is the most important factor and the difference of the $\kappa$ does not play such an important rule.

The relationship between the voltage signal and the $\mathrm{H}_{2}$ concentration is shown in Fig. 5. The $\Delta \mathrm{V}$ of the micro-THS is nonlinear at a low $\mathrm{H}_{2}$ concentration due to the low catalytic activity and concentration errors in the test mixture gas. The $\Delta \mathrm{V}$ of the micro-THSs using the Si thin films was larger than that of the micro-THS using the SiGe thin film due to the high $\alpha$ value. It appears that the micro-THS using the Si thin films can achieve a high sensitivity to detect low $\mathrm{H}_{2}$ concentrations compared to that using the SiGe thin film.

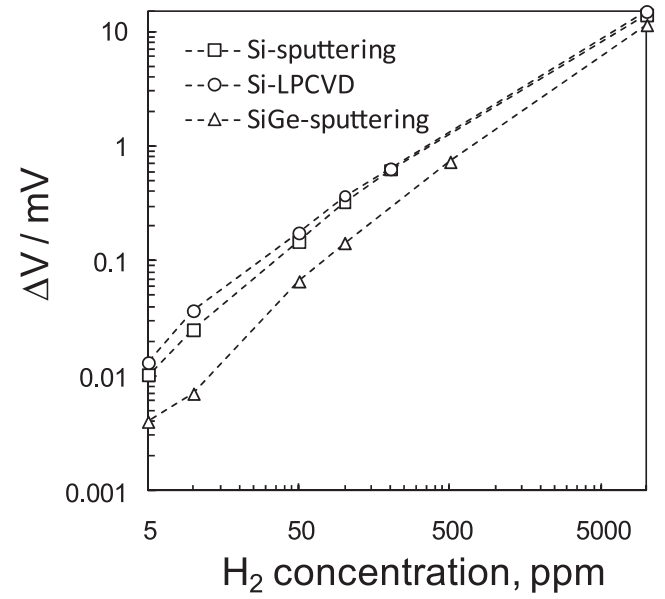

Fig. 5. Response of the micro-THS with various Si-sputtering, SiLPCVD, and SiGe-sputtering TE thin films for $\mathrm{H}_{2}$ concentrations from $100 \mathrm{ppm}$ to $1 \mathrm{ppm}$.

\section{Conclusion}

Si thin films were deposited on an $\mathrm{Si}_{3} \mathrm{~N}_{4} / \mathrm{SiO}_{2}$ multilayer on $\mathrm{Si}$ substrate using the helicon sputtering and LPCVD methods, and micro-THSs using these thin films were fabricated. The $\alpha$ of the Si thin films were $107-246$ and $182-235 \mu \mathrm{V} / \mathrm{K}$ at temperatures of between 50 and $480^{\circ} \mathrm{C}$, and were $50 \%$ larger than that of SiGe-sputtering thin film. The temperature differences of the micro-THSs with the Si-sputtering, Si-LPCVD, and SiGesputtering were 42,35 , and $45^{\circ} \mathrm{C}$. On the other hand, the $\Delta \mathrm{V}$ of the micro-THSs with the Si-sputtering and Si-LPCVD TE thin films were approx. 8 and $13 \%$ larger than that with SiGesputtering TE thin film, respectively. Both the TE properties of the thin films and sensing performances of the micro-THSs with the Si thin films were better than the SiGe thin film, although the temperature differences for the micro-THSs with the Si thin films were smaller compared to that with the SiGe thin film.

The $\kappa$ of the Si thin films (around $30 \mathrm{~W} / \mathrm{mK}$ ) were much larger than that of the SiGe thin film $(\sim 10 \mathrm{~W} / \mathrm{mK})$. However, the difference of the $\Delta \mathrm{T}$ between the micro-THSs with the Si thin films and the SiGe thin film is not so large. In general, the low thermal conductivity of the thermoelectric materials proved to be the most important factor to increase the output signal in the case of bulk generators. For the gas sensing performance of the microTHS with the TE thin film, it is important that the TE thin film has high thermoelectric properties and the $\Delta \mathrm{V}$ of the micro-THS mostly depends on the $\alpha$ of the TE thin film. Therefore, to improve the $\Delta \mathrm{V}$ of the micro-THS, it is important to use thermoelectric materials of high $\alpha$ rather than those with low $\kappa$. 


\section{Reference}

1) K. Ihokura and J. Watson, "The Stannic Oxide Gas Sensor Principles and Applications," CRC Press, Boca Raton (1994).

2) A. Katsuki and K. Fukui, Sens. Actuators B, 52, 30-37 (1998).

3) W. Shin, K. Imai, N. Izu and N. Murayama, Jpn. J. Appl. Phys., Part 2, 40, L1232-L1234 (2001).

4) W. Shin, M. Matsumiya, N. Izu and N. Murayama, Sens. Actuators B, 93, 304-308 (2003).

5) M. Nishibori, W. Shin, N. Izu, T. Itoh, I. Matsubara, S. Yasuda and S. Ohtani, Int. J. Hydrogen Energy, 34, 2834-2841 (2009).

6) K. Tajima, F. Qiu, W. Shin, N. Sawaguchi, N. Izu, I. Matsubara and N. Murayama, Jpn. J. Appl. Phys., 43, 5978-5983 (2004).

7) W. Shin, M. Nishibori, N. Izu, T. Itoh and I. Matsubara, $J$. Electron. Mater., in press.

8) M. Nishibori, W. Shin, L. F. Houlet, K. Tajima, N. Izu, T. Itoh, N. Murayama and I. Matsubara, J. Ceram. Soc. Japan, 114, 853-856 (2006).
9) M. Nishibori, W. Shin, N. Izu, T. Itoh and I. Matsubara, Sens. Actuators B, 137, 524-328 (2009).

10) M. Strasser, R. Aigner, M. Franosch and G. Wachutka, Sens. Actuators A, 97-98, 535-542 (2002).

11) O. Yamashita, J. Appl. Phys., 95, 178-183 (2004).

12) W. Shin, M. Ishikawa, M. Nishibori, N. Izu, T. Itoh and I. Matsubara, Mater. Trans., 50, 1596-1602 (2009).

13) W. Shin, Y. Choi, K. Tajima, N. Izu, I. Matsubara and N. Murayama, Sens. Actuators B, 108, 455-460 (2005).

14) W. Shin, M. Nishibori, Y. Choi, K. Tajima, N. Izu, I. Matsubara and N. Murayama, Sens. Actuators B, 118, 283-291 (2006).

15) Y. Choi, K. Tajima, W. Shin, N. Izu, I. Matsubara and N. Murayama, J. Mater. Sci., 41, 2333-2338 (2006).

16) M. von Arx, O. Paul and H. Baltes, J. Microelectromech. Syst., 9, 136-145 (2000)

17) C. B. Vining, "Silicon/germanium," Ed. by D. M. Rowe, CRC Handbook of thermoelectrics, CRC Press, Boca Raton (1995). 